\title{
Anthony Chiva and Jill Manthorpe (eds.) (2009). Older Workers in Europe. Maidenhead: Open University Press, 177 pp. ISBN 9780335 222759 (paperback)
}

\author{
REVIEWED BY DIRK HOFÄCKER*
}

In virtually all modern societies, the increasing financial strain on pension systems, triggered by demographic shifts, has been amplified by a longterm trend towards ever earlier exit of older workers from the active labour force. Thus, the future of work and retirement has remained one of the most vividly discussed topics in both public and academic discourse. In line with the political timeliness, there has been much research on the drivers underlying the long-term development towards early employment exit. However, as yet, little research has provided comparable insight into recent attempts to reverse this trend. Indeed, many European societies have undergone a paradigm shift from an "exclusive" policy of shedding the older workforce towards the "inclusive" principle of active ageing, reflected in some notable improvement in older workers' employment. However, the necessary actions at the level of national policymaking, firmlevel workplace policies and individual-level retirement planning and behaviour, required to turn these first successes into a sustainable longterm trend, still remain under-researched.

Against this background, the book by Chiva and Manthorpe on Older Workers in Europe makes a welcome contribution to the current state

*Dirk Hofäcker, Mannheim Centre for European Social Research (MZES), University of Mannheim, Germany 
International Journal of Ageing and Later Life

of knowledge, as it integrates an overview of recent developments in older workers' employment with a description of current labour market and workplace policies as well as new innovative approaches to promote longer working lives. The chapters of the book are written by a broad range of authors, bringing together well-known academics as well as experienced practitioners in the field.

The two introductory chapters, written by the editors and Sarah Harper, set the scene for the further chapters of the book by identifying key issues in older workers' employment from a conceptual and historical perspective. The subsequent two chapters supplement this theoretical focus with selected empirical evidence. Based on results from the CROW survey, Matthew Flynn and Steve McNair show that the willingness of older British employees to continue working may be generally higher than oftentimes assumed. However, at the same time, they illustrate the interindividual variation in working desires and retirement attitudes, ranging from job-mobile employment "enthusiasts" to mostly female "detachers" working under unfavourable employment conditions and thus exhibiting a clearly lower desire to continue working. Phillip Taylor's cross-national comparison of employment trends and political initiatives makes a similar point when arguing that not all older workers may benefit from recent activation policies: While those with high human capital may gain more freedom in their decision to retire, those with lesser skills could become "trapped on an unemployment hinterland" with bleak employment prospects, while at the same time facing increasing expectations to prolong their working life (p. 50+).

The following chapters turn the perspective from the overall picture to more detailed accounts of older workers' employment in specific economic sectors. Kerry Platman describes older workers' employment in the British IT sector in which the need for swift adaptability on highly competitive global markets have often restricted the development of policies to enhance longer work lives. Jill Manthorpe and Jo Moriarty, in contrast, show that in the social care sector, older workers may become a highly attractive workforce as "experts by experience", although this development is still in its infancy. Similar potential may lie in health services such as nursing and midwifery. However, as Jo Aspland and colleagues show in their later chapter, huge research gaps remain about 
the work situation and the needs of older workers in these sectors that impede the effective design of targeted measures to encourage their employment.

The subsequent contributions by Patrick Grattan and Chris Phillipson, respectively, start a series of chapters that focus more explicitly on the effective design of employment policies and active ageing programmes. Both authors highlight that the emergence of ever more "variable career patterns" and "changing life course transitions" creates new challenges for the educational system to better integrate older workers. Elizabeth Farmer and Jill Soulsby provide an impressive insight into the concrete potentials and barriers of employment programmes for older workers with their report about the development of the "East-Midlands Mature Workforce Initiative". Chiva and colleagues finally complement these national perspectives on the UK with an overview over a transnational project aimed at a better management of later life changes by developing effective career planning materials.

As the authors themselves state in the jacket text, the book brings together an "extraordinarily diverse" perspective on older workers' employment and its relevant determinants at the political, individual and workplace level. The book effectively avoids the frequent fallacy to overgeneralise findings across the "entire older workforce" or to overestimate the isolated influence of single determinants on older workers' employment behaviour. Instead, it highlights the complexity of intertwined factors in reversing the early exit trend: nation-state level policies to foster the employment of older workers need to be supplemented by effective workplace policies at the firm-level as well as a self-reliant career planning at the individual level. This simultaneous consideration of various different levels, fostered by the broad spectrum of authors, is truly unique and deserves much praise.

The flipside of the wide scope of the book is, however, that both its quintessence and its practical applications remain somewhat ambiguous. The scope of authors and consequently the style of chapters varies considerably, ranging from theoretically driven research papers to largely descriptive project accounts. Although the opening chapters of the book provide an informative introduction into the topic as such, they do not establish a common conceptual or theoretical framework that binds together the contributions or establishes relations between the various contexts of older 
International Journal of Ageing and Later Life

workers' employment. It remains, for example, an open question whether the concrete political initiatives described in the latter part would work in different contextual settings or whether they are "context-dependent" on specific necessary conditions at the national policy level outlined in the book's opening chapters. As many of the contributions to the volume focus largely on the United Kingdom, it also remains unclear whether the findings can be generalised to a broader European scope, i.e. to countries with different types of pension systems, labour market policies and labour relations. In this sense, the book thus may not entirely answer all expectations by scientists interested in broader generalisations or practitioners looking for more concrete policy advice.

However, these expectations would be excessively high targets in the still largely emerging field of research on older workers' employment prospects under the new "active ageing" paradigm. A more realistic aim, put forward by the editors themselves, may be to provide first partial answers to key questions and to "trigger reader's own thinking" beyond these (p. 2). This aim has most certainly been met with this multifaceted volume that can be recommended to both academics and practitioners with an interest in the future of work and retirement. At the same time, it could turn into a fruitful starting point and major stimulus for the future studies urgently needed in this relevant field of research. 